\title{
Periodontal conditions of Colombian university students aged 16 to 35
}

\section{Ana María MARULANDA Diana CORAL Diego SABOGAL Carlos SERRANO}

Departamento de Ciencias Básicas y Medicina Oral, Facultad de Odontología, Universidad Nacional de Colombia, Bogotá, Bogotá D.C., Colombia.

Declaration of Interests: The authors certify that they have no commercial or associative interest that represents a conflict of interest in connection with the manuscript.

Corresponding Author:

Carlos Serrano

E-mail: caserranom@unal.edu.co

DOI: 10.1590/1807-3107BOR-2014.vol28.0009 Epub XXX XX, 2014

Submitted: Aug 31, 2013

Accepted for publication: Jan 13, 2014

Last revision: Feb 13, 2014

\begin{abstract}
Epidemiological data on the periodontal health and oral hygiene practices of young individuals in Latin America are limited. This study was conducted in a sample of 355 first-year students randomly selected from 3,251 new students entering the largest university in Colombia. Participants received a periodontal examination and were interviewed about oral hygiene practices. Specifically, this study assessed the relationship between oral hygiene practices (including smoking tobacco) and plaque accumulation and/or periodontal bleeding on probing (BOP). Participants had extensive plaque accumulation and BOP, with a mean O'Leary plaque index of $56 \%$ and mean BOP of $37 \%$. Both measures were higher for proximal surfaces. Plaque indices of at least $50 \%$ were not associated with any oral hygiene factors; however, plaque index and use of dental floss were associated with a BOP of at least $50 \%$. Frequency of tooth brushing was higher in female than in male participants. Only $5 \%$ of participants reported smoking tobacco. On average, participants had $2.7 \pm 4.6$ pockets of at least $4 \mathrm{~mm}$ (18\% of participants had $\geq 5$ and $9 \%$ of participants had $\geq 10$ pockets of this depth, respectively). On average, participants had $2.1 \pm 4.4$ sites with clinical attachment loss of at least $2 \mathrm{~mm}(15 \%$ and $6 \%$ of participants had $\geq 5$ and $\geq 10$ sites with this level of loss). Only $8 \%$ of participants were diagnosed with moderate periodontitis, and no participants were diagnosed with severe periodontitis. In conclusion, although participants had high levels of plaque and BOP, signs of advanced destructive periodontal disease were minimal.
\end{abstract}

Keywords: Periodontitis; Dental Plaque Index; Periodontal Attachment Loss.

\section{Introduction}

Classical studies have shown that plaque accumulation leads to clinical signs of gingivitis after only a few weeks. ${ }^{1}$ Over time, chronic gingivitis can lead to loss of periodontal attachment in certain individuals. ${ }^{2}$ Epidemiological studies have revealed that advanced destructive periodontal disease is present in $5 \%$ to $15 \%$ of the population, with severe periodontal breakdown most common in individuals over the age of 40 years. ${ }^{3}$

The prevalence of periodontal disease in young individuals has been studied in diverse populations. Two recent studies of the periodontal health of 19-year-old Swedish subjects from urban and rural areas revealed high levels of plaque accumulation and gingivitis. ${ }^{4,5}$ 
Separate large epidemiological studies of the periodontal health of young individuals in Chile and Brazil found significant levels of clinical attachment loss (CAL). ${ }^{6,7}$ A 1998 Colombian study on oral health found a high prevalence of periodontal pockets and loss of periodontal attachment in younger individuals. ${ }^{8}$ Since then, however, no data on the periodontal health of a young age group in Colombia have been published.

The Universidad Nacional de Colombia is the largest university in Colombia; each semester, approximately 3,200 new students enroll at the Bogotá campus. New students complete medical and dental examinations. During the 2012 academic year, students were also offered a periodontal examination. Here, we sought to determine the periodontal health of this sample of young Colombian students.

\section{Methodology Study Sample}

Along with the routine medical and dental examinations provided to all new students at the University, a representative sample of the 3,251 students was invited to participate in a periodontal examination. Estimates of probability, standard error, and confidence intervals for finding extensive gingival disease were made on the basis of a similar study. ${ }^{8}$ The calculated minimum sample size for the study was 355 subjects. Participants were selected from among new students enrolling in each of the University's 41 study programs, using a list of consecutive numbers and proportional random assignment. If any student declined participation, the next individual on the list was invited to participate.Participants were excluded from the study if they had any systemic condition that would prevent them from undergoing a periodontal examination without medication. The study was approved by the ethical committee of the Universidad Nacional de Colombia, certificate 0-03 of 2012-02-22, and all of the participants provided written informed consent.

\section{Interview Questions}

Participants were interviewed about oral hygiene practices, including: frequency of tooth brushing, dental floss and mouthwash use, time since last dental visit, and tobacco smoking status.

\section{Clinical Examination}

Examinations were performed in a fully equipped dental office by two periodontal graduate students. Randomly selected cross-jaw quadrants were analyzed, third molars were excluded. The mesio-buccal, mid-buccal, disto-buccal, and disto-lingual surfaces were examined on each tooth. Kingman et al. $.^{9} \mathrm{com}-$ pared periodontal partial-mouth examinations to full-mouth examinations in a sample of 1,586 Brazilian subjects. Examination of three surfaces per tooth (e.g., mesio-buccal, mid-buccal, and disto-lingual), in either partial- or full-mouth examinations, resulted in the lowest absolute and relative biases for pocket depth (PD) and CAL measurements. As such, a similar examination method was used.

To determine intra-examiner reproducibility, repeated assessments were performed on five participants not included in the study. The average intra-examiner reproducibility kappa values for the examiners were 0.77 and 0.69 for the PD and CAL measurements, respectively.

\section{Clinical parameters analyzed were as follows:}

1. O'Leary plaque index (PI) on four surfaces per tooth,10 obtained with disclosing solution (Proquident Ltda., Medellín, Colombia);

2. bleeding on probing (BOP), defined as the percentage of surfaces with bleeding after probing to the base of the sulcus after a period of 10 seconds;

3. $\mathrm{PD}$, measured to the closest millimeter with a standardized periodontal probe (UNC-15, HuFriedy, Chicago, USA), increased PD was defined as a depth of at least $4 \mathrm{~mm}$;

4. gingival margin, measured as the distance from the free gingival margin to the cement-enamel junction, and

5. Clinical Attachment Level Loss (CAL) calculated as $\mathrm{CAL}=-\mathrm{PD} \pm \mathrm{GM}$.

The prevalence of Periodontitis was determined according to previously published methods. ${ }^{11}$ Moderate periodontitis was defined as the presence of at least two inter-proximal surfaces with CAL of $4 \mathrm{~mm}$ or greater, or at least two inter-proximal surfaces with PD of $5 \mathrm{~mm}$ or greater. Severe periodontitis was defined as the presence of at least two inter- 
proximal surfaces with CAL of $6 \mathrm{~mm}$ or greater and at least 1 inter-proximal surface with PD of 5 $\mathrm{mm}$ or greater.

\section{Data Analysis}

Analyses were performed using JMP v. 8.0 software (SAS Institute Inc., Cary, USA). Data are expressed as mean values \pm standard deviation or percentages. Pearson correlation analysis was used to determine the relationship of oral hygiene practices with PI and BOP scores of at least $50 \%$. The level of statistical significance was set at $p<0.05$.

\section{Results \\ Study Sample}

The sample of 355 participants had a mean age of $18.9 \pm 4.0$ years (range: $16-35$ years; Figure 1 ). Men comprised 71\% (253/355) of the sample. In the 2012 academic school year, male students outnumbered female students nearly 2:1 in new student enrollment. Smoking rates were low in the overall sample; $13.5 \%(48 / 355)$ of participants indicated that they smoked, but only 5\% (17/355) smoked five or more cigarettes per day.

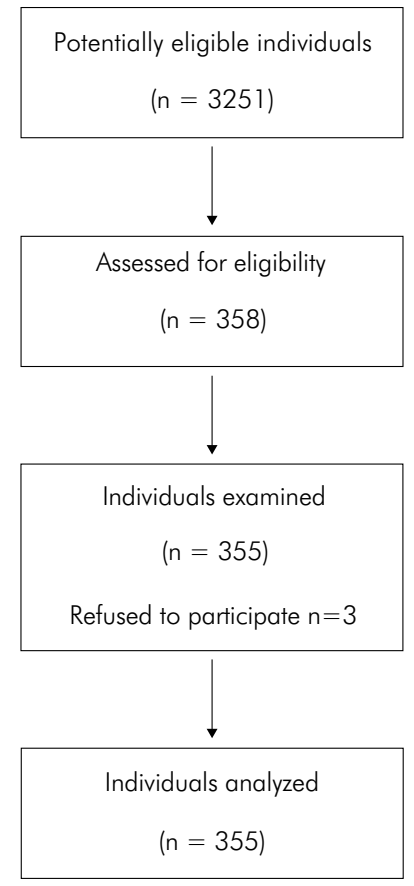

Figure 1. Number of participating students at different phases of the study.

\section{Interview Questions}

All participants indicated that they brushed their teeth daily, and $94 \%$ (334/355) of participants brushed their teeth two or more times per day. In contrast, $58 \%$ (205/355) of participants indicated that they never used dental floss; a similar trend was observed for mouthwash use (Table 1). About half $(46 \%, 164 / 355)$ of participants had visited a dentist during the last 6 months; however, 25\% (90/355) of participants had not seen a dentist in over a year. Women exhibited significantly greater frequencies of tooth brushing than men ( $p=0.0005$; Table 2).

Table 1. Frequency of oral hygiene practices among students.

\begin{tabular}{lccc}
\hline $\begin{array}{l}\text { Frequency of } \\
\text { use per day }\end{array}$ & $\begin{array}{c}\text { Tooth-brushing } \\
\mathrm{n}(\%)\end{array}$ & $\begin{array}{c}\text { Dental Floss } \\
\mathrm{n}(\%)\end{array}$ & $\begin{array}{c}\text { Mouth rinse } \\
\mathrm{n}(\%)\end{array}$ \\
\hline Never & 0 & $208(58)$ & $202(57)$ \\
Every other day & 0 & $23(7)$ & $6(2)$ \\
1 & $21(6)$ & $88(25)$ & $71(20)$ \\
2 & $78(50)$ & $26(7)$ & $58(16)$ \\
$\geq 3$ & $56(44)$ & $10(3)$ & $18(5)$ \\
\hline
\end{tabular}

Table 2. Comparison of mean frequency of oral hygiene practices between genders.

\begin{tabular}{lccc}
\hline Oral Hygiene Practice & $\begin{array}{c}\text { Male } \\
(253)\end{array}$ & $\begin{array}{c}\text { Female } \\
(102)\end{array}$ & $p$ value \\
\hline $\begin{array}{l}\text { Tooth-brushing } \\
\text { (day) }\end{array}$ & 2.36 & 2.64 & 0.0005 \\
$\begin{array}{l}\text { Dental floss } \\
\text { (day) }\end{array}$ & 0.49 & 0.57 & 0.39 \\
$\begin{array}{l}\text { Mouth rinse } \\
\text { (day) }\end{array}$ & 0.60 & 0.70 & 0.75 \\
$\begin{array}{l}\text { Last visit to the dentist } \\
\text { (month) }\end{array}$ & 13.7 & 12.2 & 0.45 \\
\hline
\end{tabular}

\section{Clinical Examination}

Most participants had all of their teeth (mean: $27.6 \pm 0.9$ teeth).The overall mean PI was $56 \%$ (27). Greater plaque accumulation was present on the proximal surfaces $(60 \%)$ compared to the buccal surfaces (43\%). Only $10 \%(37 / 355)$ of participants had a total PI of less than $20 \%$, and 55\% (195/355) had a PI of at least $50 \%$ (Figure 2). PIs were not significantly different between male (56\%) and female (55\%) participants. 


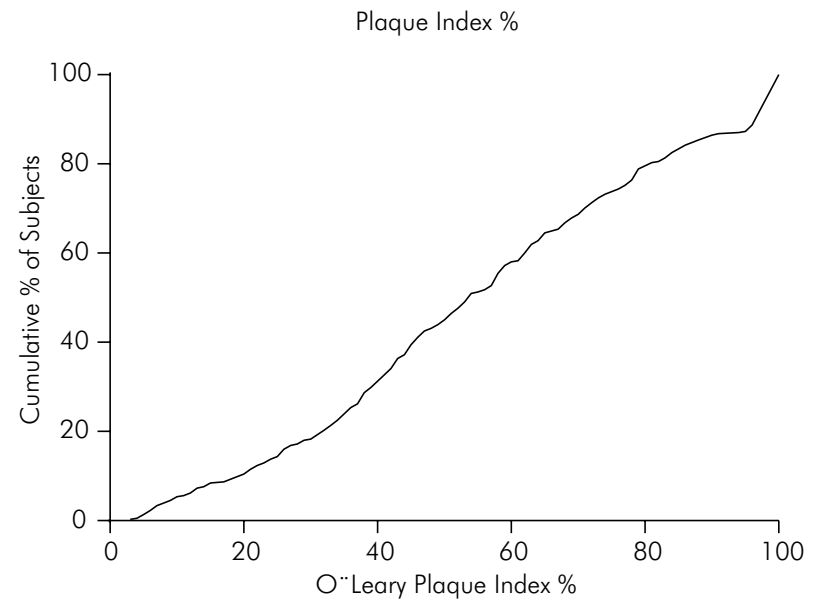

Figure 2. Cumulative percent of individuals according to the plaque index.

The participants showed high percentages of BOP. The total BOP score for participants was $37 \%$ (22). BOP scores for the proximal and buccal surfaces were $42 \%$ (23) and $25 \%$ (23), respectively. BOP scores of less than $20 \%$ were observed for $26 \%$ (91/355) of participants, whereas $24 \%(86 / 355)$ of participants had BOP scores of at least $50 \%$ (Figure 3). Similar to PI, the BOP scores were not significantly different between male $(38 \%)$ and female (34\%) participants.

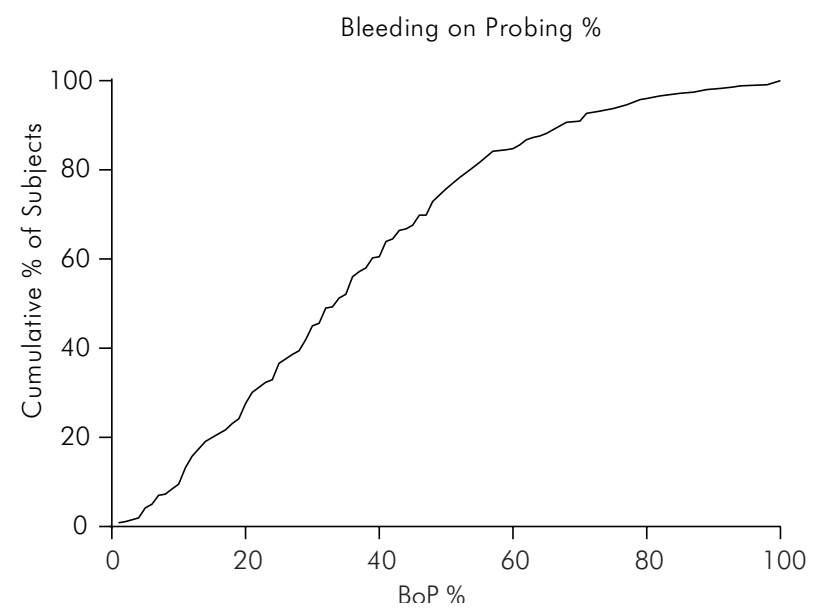

Figure 3. Cumulative percent of individuals according to bleeding on probing (\%).

Oral hygiene measures (e.g., frequency of tooth brushing, mouthwash use, etc.) were not significantly associated with PIs of at least $50 \%$. However, dental floss use $(r=0.32, p=0.03)$ and PI $(r=0.36, p=0.0002)$ were associated with BOP scores of at least $50 \%$.

Participants had minimal signs of gingival recession (GR). In our sample, 32\% (114/355) of participants had at least one, $9 \%(31 / 355)$ of participants had at least three, and only $4 \%$ (13/355) of participants had at least five GR sites with a depth of at least $1 \mathrm{~mm}$ (Table 3). Only 9\% (32/355) of participants had at least one GR site with a depth of at least $2 \mathrm{~mm}$.

The overall mean PD of the sample was $2.1(0.3)$ $\mathrm{mm}$, and $42 \%(150 / 355)$ of participants had no sites of increased PD. Among participants with periodontal pockets of at least $4 \mathrm{~mm}, 18 \%(63 / 355)$ had at least 5 pockets and $9 \%(31 / 355)$ had at least 10 pockets. Only $4 \%(13 / 355)$ of participants had sites with PD of at least $6 \mathrm{~mm}$ (Table 3).

The overall mean CAL of the sample was $0.2 \pm 0.3 \mathrm{~mm}$, and $54 \%(191 / 355)$ of participants had no sites showing CAL of at least $2 \mathrm{~mm}$. Among participants with sites showing CAL of at least $2 \mathrm{~mm}$, $15 \%(53 / 355)$ had at least 5 sites and $6 \%(23 / 355)$ had at least 10 sites (Table 3). In our sample, 10\% (35/355) of participants had at least one site showing CAL of at least $4 \mathrm{~mm}$, but only $1 \%$ (3/355) of participants had sites showing CAL of at least $6 \mathrm{~mm}$.

Overall, 8\% (29/355) of participants could be diagnosed with moderate periodontitis. No participants were found to have severe periodontitis.

\section{Discussion}

This sample of Colombian university students had high levels of plaque accumulation and BOP. Comparable levels of plaque accumulation and periodontal bleeding have been found in similar samples of young individuals coming from countries such as Brazil, Sweden, and Switzerland. A recent survey of 1,211 Brazilian children, ranging in age from 8 to 12 years, found high visible PI scores 89.7 , and a high prevalence of gingivitis, 78.5. ${ }^{12}$ Separate studies of 19 -year-old Swedish adolescents, living in urban and rural areas, found PIs that ranged from $47 \%$ to $59 \%$, and gingivitis prevalence that ranged from $44 \%$ to $56 \%{ }^{4,5}$ A study of the periodontal conditions of 624 Swiss army recruits 
Table 3. Number of sites per person with $G R \geq 1 \mathrm{~mm}, \mathrm{PD} \geq 4 \mathrm{~mm}$, and CAL loss $\geq 2 \mathrm{~mm}$.

\begin{tabular}{lccccc}
\hline Variable & Mean (SD) & Median & Quartile range & Maximum & Minimum \\
\hline Gingival recession $\geq 1 \mathrm{~mm}$ & & & & & \\
$\quad$ All surfaces & $0.78(1.7)$ & 0 & $0-1$ & 16 & 0 \\
Buccal & $0.59(1.1)$ & 0 & $0-1$ & 8 & 0 \\
PD $\geq 4 \mathrm{~mm}$ & & & & & 0 \\
$\quad$ All surfaces & $2.7(4.6)$ & 1 & $0-3$ & 34 & 0 \\
$\quad$ Proximal & $2.5(4.3)$ & 1 & $0-3$ & 28 & 0 \\
CAL loss $\geq 2 \mathrm{~mm}$ & & & & & \\
All surfaces & $2.1(4.4)$ & 0 & $0-2$ & 34 & 0 \\
Proximal & $1.5(3.7)$ & 0 & $0-1$ & 29 & 0 \\
\hline
\end{tabular}

SD: Standard deviation.

(age range: 18-24 years) found plaque and gingival indices of 1.3 (SD 0.3), and 1.2, respectively. ${ }^{13}$

A Colombian study on oral health performed a periodontal examination of 3,976 young adults aged 20 to 24 using a partial method. ${ }^{8}$ The results of the Community Periodontal Index of Treatment Needs found that $66 \%$ of the participants in that age group had levels of plaque accumulation and periodontal bleeding similar to our findings. That same study also found that gingivitis was more likely to occur in men than women, individuals with lower education levels, and individuals living in rural areas. Although our study did not find differences between men and women in plaque accumulation or periodontal bleeding, participants in our study all had completed a high school education and came mostly from urban areas.

One explanation for the high levels of plaque and gingivitis found in this sample could be that most participants (58\%) did not use dental floss. Daily flossing was associated with less dental plaque, lower calculus formation, and less gingivitis, but not $\mathrm{CAL}$, in an Australian oral health survey. ${ }^{14}$ A Cochrane systematic review by Sambunjak et al..$^{15}$ analyzed data on the effects of tooth brushing alone versus tooth brushing plus flossing, in terms of plaque accumulation, gingivitis, and caries. The authors concluded that there is some evidence showing greater gingivitis reduction with the additional use of dental floss; however, only weak evidence was found to support greater plaque reduction with the addition of floss. A systematic review by Berchier et al. ${ }^{16}$ concluded that flossing did not provide any additional benefits to tooth brushing alone on interproximal plaque and gingivitis reduction. For the present sample, no correlation was present between PIs greater than 50\% and dental floss use. Regardless, flossing for proximal plaque control should still be considered a common-sense practice. ${ }^{17}$ Similar to our results, surveys in Sweden ${ }^{4,5}$ and Australia ${ }^{14}$ have found low percentages of individuals using dental floss 3-4\% in Sweden, and 20\% in Australia.

Although $94 \%$ of participants in this study reported brushing their teeth at least twice per day, $43 \%$ of the buccal surfaces examined showed plaque accumulation. Factors other than the frequency of brushing were likely responsible for the high plaque scores. According to a study by Löe and Kleinmann, ${ }^{18}$ three main factors are associated with the efficacy of plaque removal by tooth brushing: 1) the design of the brush, 2) the skill of the individual using the brush, and 3) the frequency and duration of use. A systematic review by Slot et al. ${ }^{19}$ evaluated the efficacy of a brushing exercise on plaque scores. A meta-analysis of 59 studies revealed that a single brushing exercise reduced plaque scores from $30 \%$ to $53 \%$ of baseline. Larger reductions were found for toothbrushes with bristle tuft arrangements (flat trim, multileveled, or angled) and longer brushing times. It could be that participants in the present study did not brush for adequate durations, did not use enough care when brushing, or used ineffective toothbrushes.

Despite the high plaque scores and periodontal bleeding in the present sample, the number of sites showing periodontal pockets or loss of attachment 
was low. Only $8 \%$ of participants had moderate periodontitis, and none had severe periodontitis. A greater prevalence of attachment loss has been found in other Latin-American countries. López et al. ${ }^{6}$ studied 9,023 individuals of 12 to 21 years of age. They found that participants had, average, 3.3 to 5.4 sites with CAL of at least $2 \mathrm{~mm}$. When only interproximal sites were considered, the average number of sites with CAL decreased to 2.6 to 4.3 sites. A Brazilian study by Susin et al. ${ }^{7}$ found that $43 \%$ of the 612 young adult participants (age: 14-29 years) met diagnostic criteria for chronic periodontitis, which they defined as having at least two teeth with CAL of at least $3 \mathrm{~mm}$.

Due to the use of different threshold diagnostic criteria for periodontitis between this study and others, direct comparison is difficult. However, these contrasting results could be due, in part, to the partial examination method used in our study. Compared to full-mouth examinations, partial-mouth examinations have been found to underestimate the presence of PD and CAL loss. ${ }^{20}$ The results of the Colombian National Study revealed that only $3 \%$ of the 20- to 24-year-old participants had a CAL loss of at least $3 \mathrm{~mm}$, a figure closer to our present findings. However, $11 \%$ of 30 - to 34 -year-old participants had a CAL of at least $3 \mathrm{~mm}$. The National Study also found greater CAL in individuals with lower socio-

\section{References}

1. Löe $H$, Theilade E, Jensen SB. Experimental gingivitis in man. J Periodontol. 1965 May;36(3):177-187.

2. Schätzle M, Löe H, Bürgin W, Anerud A, Boysen H, Lang NP. Clinical course of chronic periodontitis. I. Role of gingivitis. J Clin Periodontol. 2003 Oct;30(10):887-901.

3. Hugoson A, Sjödin B, Norderyd O. Trends over 30 years, 1973-2003, in the prevalence and severity of periodontal disease. J Clin Periodontol. 2008 May;35(5):405-14.

4. Abrahamsson KH, Koch G, Norderyd O, Romao C, Wennstrom JL. Periodontal conditions in a Swedish city population of adolescents: a cross-sectional study. Swed Dent J. 2006 Jan;30(1):25-34.

5. Ericsson JS, Abrahamsson KH, Ostberg AL, Hellstrom MK, Jonsson K, Wennstrom JL. Periodontal health status in Swedish adolescents: an epidemiological, cross-sectional study. Swed Dent J. 2009 Jul;33(3):131-9. economic status. Unfortunately, socioeconomic data were not collected in our study.

Only $5 \%$ of participants in the present study smoked at least five cigarettes per day, a lower smoking rate than in other countries. López et al. ${ }^{6}$ found that nearly $25 \%$ of the adolescent participants in Chile were daily smokers. A study by Vered et al..$^{21}$ found that $36 \%$ of the 7,056 Israeli army recruit participants were smokers, with $21 \%$ smoking more than 10 cigarettes per day. Rothlisberger et al. ${ }^{13}$ found that $32 \%$ of the 626 Swiss army recruit participants described themselves as smokers.

\section{Conclusion}

The results of the present study found on young Colombian university students high plaque accumulation and periodontal BOP. However, signs of destructive periodontal disease were minimal at this age. Only $8 \%$ of participants met diagnostic criteria for moderate periodontitis, and no participants met diagnostic criteria for severe periodontitis.

\section{Acknowledgements}

This study received financial support from the Research Office of the Universidad Nacional de Colombia (protocol no. 15653). The authors have no conflicts of interest.
6. López R, Fernández O, Jara G, Baelum V. Epidemiology of clinical attachment loss in adolescents. J Periodontol. 2001 Dec;72(12):1666-74.

7. Susin C, Haas AN, Valle PM, Oppermann RV, Albandar JM. Prevalence and risk indicators for chronic periodontitis in adolescents and young adults in south Brazil. J Clin Periodontol. 2011 Apr;38(4):326-33.

8. Franco AM, Suarez E, Tovar S, Jácome S, Ruiz JA. Tercer estudio nacional de salud buco-dental. Bogotá (Colombia): República de Colombia, Ministerio de Salud Ed; 1999.Tomo VII, Enfermedad Periodontal; p. 99-108.

9. Kingman A, Susin C, Albandar JM. Effect of partial recording protocols on severity estimates of periodontal disease. J Clin Periodontol. 2008 Aug;35(8):659-67.

10. O'Leary TJ, Drake RB, Naylor JE. The plaque control record. J Periodontol. 1972 Jan;43(1):38. 
11. Page RC, Eke PI. Case definitions for use in populationbased surveillance of periodontitis. J Periodontol. 2007 Jul;78(7 Suppl):1387-99.

12. Chiapinotto FA, Vargas-Ferreira F, Demarco FF, Correa FOB, Masotti AS. Risk factors for gingivitis in a group of Brazilian schoolchildren. J Public Health Dent. 2013 Winter;73(1)9-17.

13. Röthlisberger B, Kuonen P, Salvi GE, Gerber J, Pjetursson BE, Attström R, et al. Periodontal conditions in Swiss army recruits: a comparative study between the years 1985, 1996 and 2006. J Clin Periodontol. 2007 Oct;34(10):860-6.

14. Crocombe LA, Brennan DS, Slade GD, Loc DO. Is self-interdental cleaning associated with dental plaque levels, dental calculus, gingivitis, and periodontal disease?. J Periodontal Res. 2012 Apr;47(2):188-97.

15. Sambunjak D, Nickerson J, Poklepovic T, Johnson T, Imai P, Tugwell $\mathrm{P}$, et al. Flossing for the management of periodontal diseases and dental caries in adults. Cochrane Database Syst Rev. 2011 Dec 7;(12):CD008829. DOI: 10.1002/14651858. CD008829.pub2.
16. Berchier CE, Slot DE, Haps S, Van der Wejden GA. The efficacy of dental floss in addition to a toothbrush on plaque and parameters of gingival inflammation: a systematic review. Int J Dent Hyg. 2008 Nov;6(4):265-79.

17. Van der Wejden F, Slot DE. Oral hygiene in the prevention of periodontal diseases: the evidence. Periodontol 2000. 2011 Feb;55(1):104-23.

18. Löe H, Kleinmann D. Dental plaque control measures and oral hygiene practice. Oxford: IRL Press Ltd.; 1985. Chapter 1, Practice: state of the art review; p. 3-119.

19. Slot DE, Wiggelinkhuizen L, Rosema NAM, Van der Wejden GA. The efficacy of manual toothbrushes following a brushing exercise: a systematic review. Int J Dent Hyg. 2012 Aug;10(3):187-97.

20. Kingman A, Albandar JM. Methodological aspects of epidemiological studies of periodontal diseases. Periodontol 2000. 2002 Apr;29(1):11-30.

21. Vered Y, Livny A, Zini A, Sgan-Cohen HD. Periodontal health status and smoking among young adults. J Clin Periodontol. 2008 Sep;35(9):768-72. 